\title{
Determination of apramycin in oral soluble powder by a HPLC method using pre-column derivatization with o-phthalaldehyde and UV detection
}

\author{
Elisabete de Almeida Barbosa Antunes*, Felipe Rebello Lourenço, \\ Terezinha de Jesus Andreoli Pinto
}

Departamento de Farmácia, Faculdade de Ciências Farmacêuticas, Universidade de São Paulo

\begin{abstract}
A high-performance liquid chromatographic method employing pre-column derivatization with o-phthalaldehyde (OPA) and 2-mercaptoacetic acid was developed for the determination of apramycin, an aminoglycoside antibiotic used in veterinary medicine, in the oral soluble powder form. The chromatographic separation was done by ion-pair HPLC using a C18 reversed-phase column, Synergy Hydro $(150 \mathrm{~mm} \times 4.6 \mathrm{~mm} \times 4 \mu \mathrm{m})$ and mobile phase composed of $0.005 \mathrm{~mol} / \mathrm{L}$ sodium octanosulfonate in a mixture of acetonitrile: water: acetic acid (45:55:2) (v/v/v) with a flow rate of $1.0 \mathrm{~mL} / \mathrm{min}$; the UV detector was operated at $332 \mathrm{~nm}$. The developed method was validated according to official compendia guidelines, having demonstrated robustness, selectivity and linearity for the concentration range of 0.02 to $0.05 \mathrm{mg} / \mathrm{mL}$, precision (with RSD $<2.0 \%$ both for intra and inter-day precision) accuracy (average recuperation of $99.33 \%$ ) and detectivity (quantification and detection limits of 0.08 and $0.02 \mu \mathrm{g} / \mathrm{mL}$, respectively). Three batches of commercial apramycin oral soluble powder were analyzed by both the proposed method and the official microbiological method, where all the results obtained were in the acceptable range ( $95 \%$ to $105 \%$ of labeled value of apramycin). Both methods were statistically compared by the $t$ test, which yielded no significant differences $(\alpha=0.05)$ thereby confirming the equivalence of the methods.
\end{abstract}

Uniterms: Apramycin. HPLC. Microbiological Assay. Pre-column Derivatization. OPA.

Foi desenvolvido um método por cromatografia líquida alta eficiência empregando derivatização précoluna com $o$-ftalaldeído (OPA) e ácido mercaptoacético para determinação de apramicina, um antibiótico aminoglicosídeo de uso veterinário, em pó oral solúvel. A separação cromatográfica foi feita por fase reversa com pareamento iônico utilizando-se coluna Synergy Hydro C18 (150 x 4,6 mm x $4 \mu \mathrm{m})$ e fase móvel composta por octanossulfonato de sódio $0,005 \mathrm{~mol} / \mathrm{L}$ em mistura de acetonitrila:água:ácido acético nas proporções 45:55:2 (v/v/v), numa vazão de $1.0 \mathrm{~mL} / \mathrm{min}$; efetuou-se detecção por UV a $332 \mathrm{~nm}$. O método foi validado de acordo com os compêndios oficiais e demonstrou robustez, seletividade, linearidade na faixa de 0,02 a $0,05 \mathrm{mg} / \mathrm{mL}$, precisão (com DPR $<2,0 \%$ tanto para a precisão intra-dia quanto para a precisão inter-dia), exatidão (recuperação média de 99,33\%) e detectabilidade (limite de quantificação e de detecção iguais a 0,08 e $0,02 \mu \mathrm{g} / \mathrm{mL}$, respectivamente). Analisaram-se 3 lotes de apramicina pó oral solúvel pelo método proposto e pelo método microbiológico oficial e todos os resultados obtidos estavam dentro do limite de aceitação (95\%-105\% valor rotulado de apramicina). Ambos os métodos foram comparados estatisticamente pelo teste t, não sendo encontradas diferenças significativas entre eles para $\alpha=0,05$, sendo os dois equivalentes.

Unitermos: Apramicina. CLAE. Doseamento Microbiológico. Derivatização pré-coluna. OPA.

\footnotetext{
*Correspondence: E. A. Barbosa Antunes. Departamento de Farmácia-CONFAR, Faculdade de Ciências Farmacêuticas - Universidade de São Paulo. Av. Prof. Lineu Prestes, 530. B1. 13 - Cidade Universitária, 05508-000- São Paulo -SP, Brasil. E-mail: bbarbosa@usp.br
} 


\section{INTRODUCTION}

Apramycin is an aminoglycoside antibiotic produced by a strain of Streptomyces tenebrarius. It is also called nebramycin factor-2 and is characterized by a 4-amino-4deoxy-D-glucose moiety, a glycosidic linkage 1-1' and an octadiose, which forms a rigid bicyclic system, as depicted in Figure 1 (Walton, 1978; Tatsuta et al., 1984).

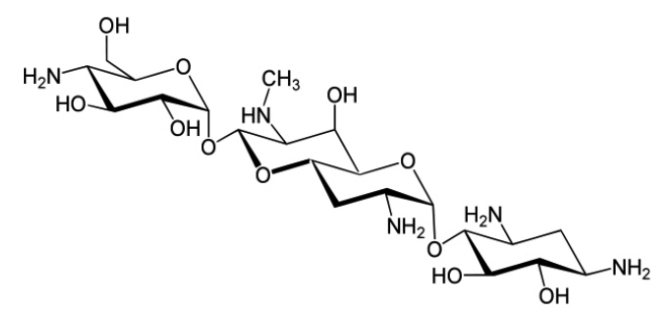

FIGURE 1 - Apramycin Chemical Structure

Its mechanism of action is based on protein synthesis inhibition both in vivo and in vitro. Apramycin is employed in veterinary medicine in injectable, premix or oral soluble powder forms, against infections caused by Gram-negative microorganisms (colibacilosis, salmonellosis, bacterial enteritis) in domestic birds, swine and calves (Perzynski et al., 1979; EMEA, 2008).

Akin to other aminoglycosides, apramycin also presents ototoxicity and nephrotoxicity as undesired side effects, a worrying aspect if the possibility of residue occurrence in the tissues of animals destined for slaughter is considered. Besides the determination of apramycin residues in food of animal sources, rigorous control of its assay in pharmaceutical preparations is required (Macneil, Ellis, 1995; Zhang et al., 2007).

British Pharmacopoeia is the only official compendium that describes apramycin (bulk pharmaceutical and its preparations), and recommends the microbiological turbidimetric assay to determine its potency (BP (Veterinary), 2008). Although microbiological methods are the main choice for determining the potency of several antibiotics, they are laborious and time-consuming techniques, with lesser precision and accuracy compared to physico-chemical methods, particularly those employing high performance liquid chromatography (HPLC), which is more accurate, precise, sensitive, specific and faster for obtaining results (Isoherranen, Soback, 1999).

HPLC has been successfully employed in the analysis of several aminoglycosides using pre- or post-column derivatization techniques, since they lack chromophore or fluorophore groups in their structure. In the specific case of apramycin, there are few published chemical methods by HPLC involving biological or animal food samples, as described by Sweeney and Coleman (1998) and Zhang et al.(2007), respectively.

Considering the several advantages offered by HPLC, the need for analytical methods to assure the efficacy and safety of apramycin pharmaceutical formulations, particularly in terms of potency and purity, as well as the absence of official physico-chemical methods for its quantification, the aim of this work was to develop and validate a new method for apramycin determination in oral soluble powder employing high performance liquid chromatography, and to compare the proposed method with the official microbiological turbidimetric assay.

\section{MATERIAL AND METHODS}

\section{Instrumentation and chromatographic parameters}

LC System - The HPLC system consisted of a TSP Spectra System equipped with degasser model SCM 1000, binary pump model P200, autosampler model AS3000, UV/Vis detector Model UV 2000 and fluorescence detector Model FL 3000. The system was controlled by an EasyChrom ${ }^{\circledR}$ data station. The detection was initially done by a fluorescence detector with excitation wavelength set at $230 \mathrm{~nm}$ and emission wavelength at $389 \mathrm{~nm}$. UV detection was adopted later with wavelength set at $332 \mathrm{~nm}$. The mobile phase chosen after method optimization was composed of $0.005 \mathrm{~mol} / \mathrm{L}$ sodium octanosulfonate in a mixture of acetonitrile: water: acetic acid (45:55:2) $(\mathrm{v} / \mathrm{v} / \mathrm{v})$ with a flow rate of $1.0 \mathrm{~mL} / \mathrm{min}$; injection volume was $50 \mu \mathrm{L}$.

LC Columns - Gemini C18, $250 \mathrm{~mm}$ x $4.6 \mathrm{~mm}$ x $5 \mu \mathrm{m}$, Synergy Fusion C18 $250 \mathrm{~mm} \times 4.6 \mathrm{~mm}$ x $4 \mu \mathrm{m}$ and Synergy Hydro C18, $150 \mathrm{~mm} \times 4.6 \mathrm{~mm} \times 4 \mu \mathrm{m}$, with the latter comprising the chosen column after optimization tests.

Spectrophotometers - UV/Visible Spectrophotometer Unicam, model Helyos Alpha and Visible Spectrophotometer Unicam, model Helyos $€$.

\section{Materials and reagents}

Apramycin working standard was supplied by Eli Lilly and had a potency of $873.3 \mu \mathrm{g} / \mathrm{mg}$ where the tobramycin reference standard was from the USP, lot LOB30.

Three batches of apramycin oral soluble powder with labeled value of $44.4 \mathrm{~g} / 100 \mathrm{~g}$ were supplied by Eli Lilly.

The test microorganism used, Salmonella cholerasuis ATCC 13311, was supplied by the Adolfo Lutz Institute. 
The following reagents were used: purified water from a Milli-Q ${ }^{\circledR}$ apparatus; HPLC grade acetonitrile from J.T.Baker; methanol, isopropanol, acetic acid, 1-octanossulfonic sodium salt, 2-mercaptoacetic acid, sodium chloride, potassium dihydrogen phosphate and potassium hydrogen phosphate, sodium and potassium hydroxide, also from J.T. Baker, analytical grade; 2-mercaptoethanol and $o$-phthalaldehyde (OPA), from Sigma Aldrich, analytical grade; boric acid, analytical grade, from Vetec; meat and yeast extracts, peptone dextrose and casein-soy broth, supplied by Difco.

\section{Method development and validation}

- $\quad$ Borate Buffer $\mathrm{pH} 10.4$ - Solution prepared as described in the BP 2008

- $\quad$ Borate Buffer pH 9.5 - Solution prepared according to Zhang et al. (2007)

- $\quad$ OPA Derivatization Solution I - Solution prepared according to Zhang et al. (2007)

- $\quad$ OPA Derivatization Solution II - Solution prepared as described in the BP 2008 and in USP 32

- Apramycin Test Solution - a stock solution of $0.2 \mathrm{mg} / \mathrm{mL}$ apramycin working standard in water was prepared and subsequently derivatized.

- Tobramycin Test Solution - a stock solution of $0.2 \mathrm{mg} / \mathrm{mL}$ tobramycin reference standard in water was prepared, and subsequently derivatized.

- $\quad$ Apramycin Working Solutions for Linearity - Six apramycin working standard solutions were prepared such that after their submission to derivatization the following concentrations were obtained: 0.020 , $0.026,0.032,0.034,0.040$ and $0.046 \mathrm{mg} / \mathrm{mL}$ corresponding, respectively, to $60 \%, 75 \%, 90 \%, 100 \%$, $115 \%$ and $130 \%$ of theoretical final concentration of apramycin after sample preparation. The 100\% apramycin working solution was also used in the robustness, precision and the quantification and detection limits evaluations (in this last case, after successive dilutions in water).

- Apramycin Solutions for Selectivity - Four apramycin solutions at a concentration of $0.2 \mathrm{mg} / \mathrm{mL}$ were individually submitted to different forced degradation conditions for two hours: acid and alkaline hydrolysis (with $0.1 \mathrm{~mol} / \mathrm{L} \mathrm{HCl}$ and $0.1 \mathrm{~mol} / \mathrm{L}$ $\mathrm{NaOH}$, respectively), as well as thermal (in water bath at $\left.100^{\circ} \mathrm{C}\right)$ and oxidative stress $\left(3 \% \mathrm{H}_{2} \mathrm{O}_{2}\right.$ aqueous solution). Four excipient solutions of sodium bicarbonate (oral soluble powder excipient) at a theoretical concentration of $0.55 \mathrm{mg} / \mathrm{mL}$ were also submitted to the same forced degradation conditions.
After the exposure period, each solution was derivatized as described below. In the specific case of acid and alkaline hydrolysis, solution neutralization was done before the mentioned procedure.

Apramycin Working Solutions for Accuracy - The recuperation technique was employed to evaluate accuracy. Initially, a $1.1 \mathrm{mg} / \mathrm{mL}$ sodium bicarbonate solution was prepared. Known concentrations of apramycin working standard were then added to give, after the derivatization procedure, three concentration levels $(0.032 \mathrm{mg} / \mathrm{mL} ; 0.040 \mathrm{mg} / \mathrm{mL}$ and $0.046 \mathrm{mg} / \mathrm{mL}$ ) where each level was prepared in triplicate.

\section{Apramycin assay by HPLC method}

Samples of each batch of soluble oral powder were prepared in triplicate in such a way that the theoretical apramycin concentration for each sample, after derivatization, was $0.034 \mathrm{mg} / \mathrm{mL}$. The linear equation obtained from the calibration curve (Apramycin Peak area versus Apramycin Concentration) was used to calculate the assay, considering sample dilutions.

\section{Derivatization procedure}

Volumes of $10.0 \mathrm{~mL}$ and $1.0 \mathrm{~mL}$ of OPA I or OPA II derivatization solution were added to a $50 \mathrm{~mL}$ actinic volumetric flask. After mixing, the volume was completed with water, and the solution left to rest for 60 minutes. The solution was then filtered through a Millex ${ }^{\circledR} 0.45 \mu \mathrm{m}$ into a vial, $50 \mu \mathrm{L}$ of which was injected into the HPLC system. In the selectivity tests with tobramycin, $10.0 \mathrm{~mL}$ of apramycin, and $10.0 \mathrm{~mL}$ of tobramycin test solution, were added to a $50 \mathrm{~mL}$ actinic volumetric flask, where derivatization was done according to the procedure outlined above. Blank solution preparation consisted only of OPA derivatization solution and the diluent - water.

\section{Apramycin turbidimetric assay}

Samples of each batch of soluble oral powder were prepared in triplicate and submitted to microbiological turbidimetric assay according to BP 2008 guidelines, with the exception of culture medium (medium $\mathrm{C}$ was employed, instead of the recommended medium $\mathrm{H}$ ) and the assay design ( 5 x 1 model was adopted, instead of $3 \times 3$ ). The potency of apramycin was calculated by a linear equation obtained from the calibration curve $\%$ Transmittance versus Log Apramycin Concentration, with the appropriate transformations while considering sample dilutions. 


\section{RESULTS AND DISCUSSION}

\section{Method Development}

Apramycin is a highly polar and hydrophilic compound (Martindale, 2007) and similar to other aminoglycosides, also lacks chromophore or fluorophore. These properties justify the use of water as diluent, ion-pairing reversed phase chromatography, and of the derivatization technique, which was performed with $o$-phthalaldehyde (OPA) in the presence of a thiol, because of several advantages: OPA has no native fluorescence, is not hazardous, is low cost, reacts readily at room temperature and is stable in aqueous solutions with $\mathrm{pH}<11.5$. (Fabre et al., 1989; Caturla, Cusido, 1992; Dorresteijn et al., 1996; Isoherranen, Soback, 1999; Stead, 2000; Zhang et al., 2007).

Considering these advantages and based on the apramycin determination carried out by Sweeney and Coleman and Zhang et al., the following chromatographic conditions were adopted to initiate method development: pre-column derivatization with OPA in the presence of 2-mercaptoethanol with reaction time of 35 minutes; reversed phase separation with a Gemini C18 column of $250 \mathrm{~mm} \times 4.5 \mathrm{~mm} \times 5 \mu \mathrm{m}$; mobile phase composed of $40 \%$ acetonitrile and $60 \%$ aqueous solution composed of acetic acid and sodium octanosulfonate as an ion pairing reagent, at a flow rate of $1.0 \mathrm{~mL} / \mathrm{min}$; injection volume of $50 \mu \mathrm{L}$; fluorescence detection with excitation at $230 \mathrm{~nm}$ and emission at $390 \mathrm{~nm}$.

Under these conditions, the apramycin peak was eluted at about 22 minutes, with resolution of 1.76 and tailing factor of 1.97. Subsequently, modifications were made in order to decrease peak retention time and improve performance of the chromatographic method. The best results were attained with the addition of $5 \%$ more acetonitrile to the mobile phase and with the use of a reduced size Synergy Hydro C18 column (150 mm x $4.6 \mathrm{~mm}$ x $4 \mu \mathrm{m})$, which supplied an apramycin peak with resolution of 2.76, tailing factor of 1.44 and retention time of about 11 minutes.

Since the apramycin peak was in fact due to isoindol derivative from the complete reaction of its four primary amines with OPA in the presence of 2-mercaptoethanol, the next step was to improve apramycin-OPA reaction conditions in order to assure complete reaction between them, with formation of a stable derivative in a shorter period of time. Modifications were made concerning the type of thiol and the OPA concentration employed.

When a small chain thiol is employed, such as 2-mercaptoethanol, the derivative decomposition is favored, whereas the use of a longer chain thiol provides more stability to the derivative, as is the case with mercaptoacetic acid, which also allows UV detection of the derivative (Weigand, Coombes, 1983; Claes, Busson, Vanderhaeghe, 1984; Albracht, 1987).

A comparative stability test was carried out with an apramycin test solution, derivatized in the presence of 2-mercaptoethanol with fluorescence detection (initial conditions) and with another in the presence of mercaptoacetic acid with UV detection at $332 \mathrm{~nm}$ (maximum wavelength absorption obtained in a preliminary test). Both solutions were repeatedly injected at intervals of 15 minutes, from 30 minutes of reaction to 5 hours. The results obtained were plotted on the graph Apramycin peak Area versus Reaction Time shown in Figure 2. It was confirmed that, the derivative formed in the presence of 2-mercaptoethanol, rapidly self-degrades whereas the other formed in the presence of mercaptoacetic acid was more stable. Therefore, this second condition was adopted.

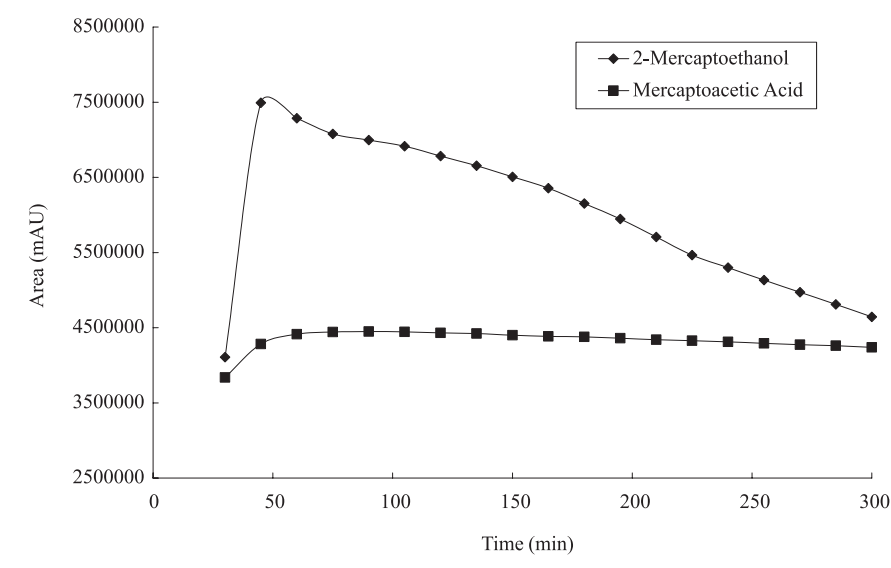

FIGURE 2 - Graph Area versus Time of formation and decomposition of the apramycin-OPA derivative, formed in the presence of 2-mercaptoethanol and fluorescence detection, and in the presence of mercaptoacetic acid and UV detection.

Concerning OPA concentration, this needed to be higher than the theoretical quantity in order to assure its complete reaction with apramycin. However, an excessive OPA concentration can accelerate the derivative decomposition rate (Stobaugh et al., 1983; Jacobs, Leburg, Madaj, 1986; Dorresteijn, 1996).

In order to determine the most suitable OPA, another stability test was also carried out comprising the derivatization of three apramycin test solutions with OPA in the presence of 2-mercaptoacetic acid in such a way that the final OPA concentrations were 2.5, 5, 10 and 50 times, respectively. This constitutes the concentration needed for complete reaction with apramycin, whose concentration 


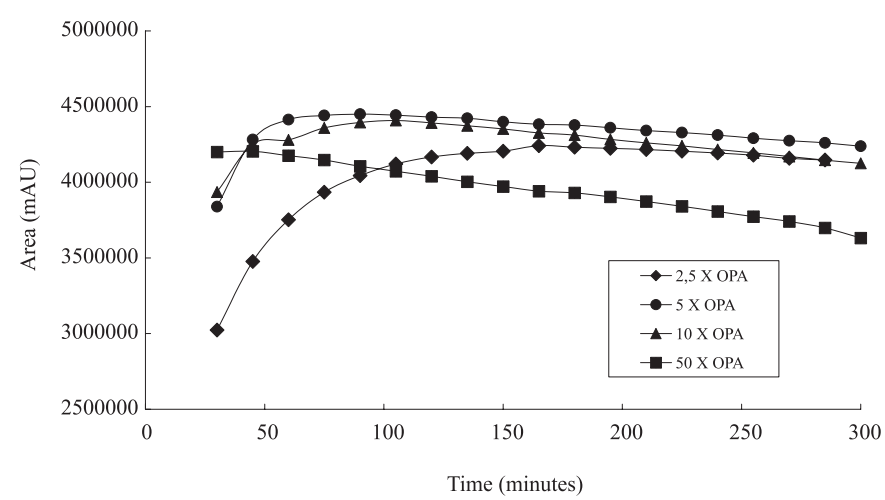

FIGURE 3 - Graph Area versus formation and decomposition Time of apramycin-OPA derivative with different OPA:apramycin concentration ratios.

remained constant. As in the first test, each solution was repeatedly injected every 15 minutes from the first 30 minutes up to 5 hours of reaction. The data obtained were plotted on the graph Apramycin Peak Area versus Reaction Time. Figure 3 shows a comparison of the graphs.

According to the graph, the most appropriate OPA: apramycin concentration ratio was $5: 1$, a proportion which had been previously used. The proportion of 2.5: 1 proved unsuitable because it took excessively long to reach the maximum formation of the OPA-Apramycin derivative (180 minutes). The proportion of 50:1 was also unsuitable because the derivative was rapidly decomposed due to very high OPA concentration. A solution with an OPA: apramycin ratio of 10:1 had similar formation and decay behavior for the derivative formed to that with a 5:1 ratio, but took longer to reach the maximum formation of the derivative.

After these improvements, the conditions adopted in this work, hereafter called "nominal method conditions", were: pre-column OPA derivatization of apramycin in the presence of mercaptoacetic acid for 90 minutes in water, with light shielding, at room temperature; $150 \mathrm{~mm}$ x $4.6 \mathrm{~mm}$ x $4 \mu \mathrm{m}$ Synergy Hydro C18 column at room temperature; mobile phase composed of $0.005 \mathrm{~mol} / \mathrm{L}$ sodium octanosulfonate dissolved in a mixture of acetonitrile: water: acetic acid at a ratio of 45:55:2 $(\mathrm{v} / \mathrm{v} / \mathrm{v})$ with a flow rate of $1.0 \mathrm{~mL} / \mathrm{min}$; injection volume of $50 \mu \mathrm{L}$; UV detection at $332 \mathrm{~nm}$.

The apramycin test solution and the blank chromatogram solution assayed under these optimized conditions are shown in Figure 4. Reduced retention time and better symmetry of apramycin peak in comparison with that obtained under initial conditions are evident. In addition, no other peaks interfere with the apramycin peak in the blank chromatogram.

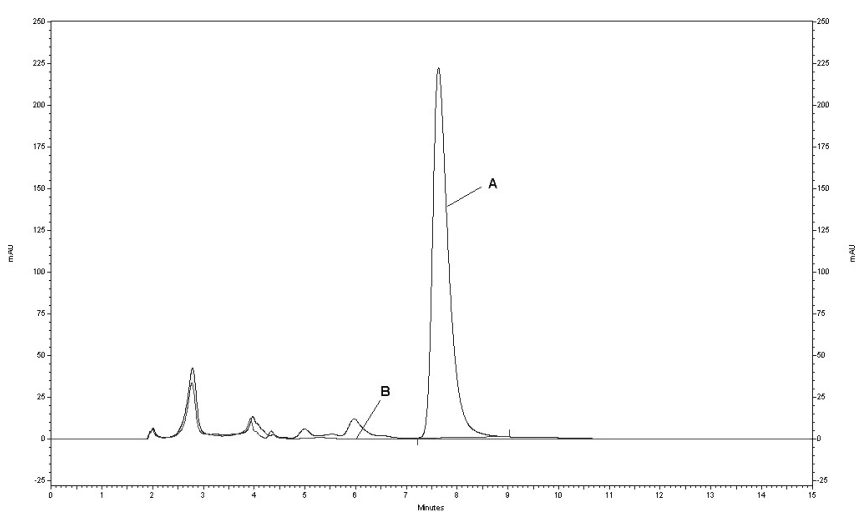

FIGURE 4 - Chromatographic profile of apramycin test solution (A) and blank solution (B) obtained with nominal method conditions after optimization.

\section{Method validation}

Validation of the proposed method was performed according to the guidelines of the International Conference on Harmonization (ICH guidelines, 2006) and the United States Pharmacopoeia (USP 32), in order to confirm its suitability for the intended purpose.

Method robustness was demonstrated by resistance to slight alterations in the mobile phase composition (acetonitrile proportion and acetic acid added volume), the OPA concentration, as well as column batch and temperature.

The second parameter to be evaluated was selectivity. As the proposed method was similar to others employed in aminoglycoside determination, it was decided to verify initially whether the method response to apramycin was unique, even in the presence of similar compounds. As it was impossible to test apramycin with all the aminoglycosides, tobramycin was chosen because is the most similar to it, and produced by the same microorganism strain and nebramycin derivative, and therefore more likely to cause interference. For the test, an apramycin test solution, tobramycin test solution and a mixture of both, were prepared and derivatized using the established method conditions. The comparison among chromatograms obtained showed that the tobramycin peak did not interfere with that of apramycin, with a relative retention of 1.2 and resolution of 3.3.

The second step of the selectivity evaluation was to verify the possible interference of apramycin degradation products. Since their working standards were not available, four $100 \%$ apramycin working solutions, along with four excipient solutions, were submitted to the following forced degradation conditions: acid, alkaline hydrolysis, oxidation, besides thermal degradation. The chromato- 
grams of apramycin solution obtained from each kind of degradation were compared with those of a $100 \%$ apramycin working solution (not submitted to degradation) the diluent and the placebo solution, as shown in Figure 5. Under the four conditions, no formation of peaks that could interfere with the apramycin peak, were observed, only some alterations to its area and, in the case of oxidative hydrolysis, an absence of it. These occurrences cannot be solely due to possible apramycin degradation, but also to modifications in the apramycin-OPA reaction conditions, resulting in incomplete or non-occurring reaction.

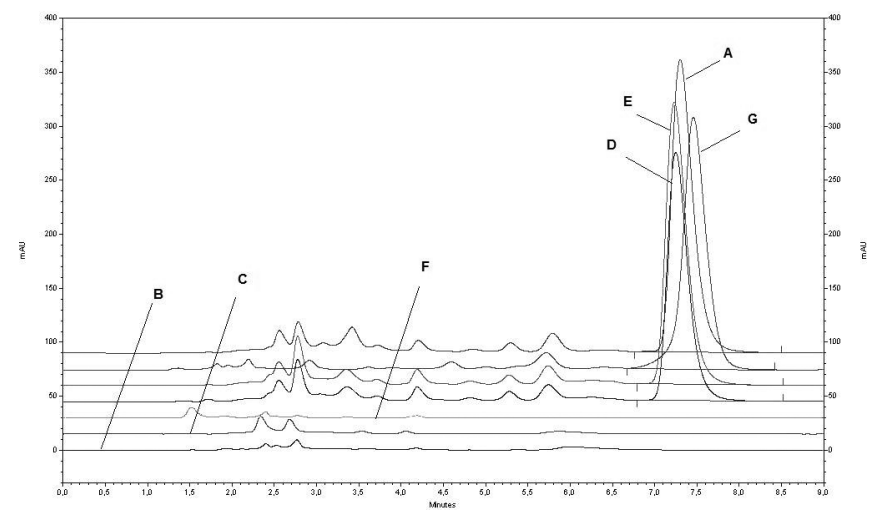

FIGURE 5 - Selectivity Evaluation: Comparison among chromatographic profiles of $100 \%$ apramycin working solution (A), diluent (B), placebo solution (C), apramycin solution submitted to acid hydrolysis (D), apramycin solution submitted to alkaline hydrolysis (E), apramycin solution submitted to oxidative degradation (F) and apramycin solution submitted to thermal degradation $(G)$. Chromatograms obtained under nominal method conditions.

The method linearity was demonstrated in the range 0.02 to $0.05 \mathrm{mg} / \mathrm{mL}$ of apramycin concentration, the calibration curve having a linear equation equal to $\mathrm{y}=132887304.98 \mathrm{x}+127223.84$ and a good correlation coefficient $(\mathrm{r}=0.999)$.
Precision evaluation was done by determination of relative standard deviation of six consecutive injections of $100 \%$ apramycin working solution (intraday precision) on three different days (inter-day precision). The low intra-day (0.39\%) and inter-day (1.09\%) values of RSD obtained demonstrated good method precision.

Accuracy was demonstrated by the recuperation test, on which the average values of $98.5 \%, 99.0 \%$ and $99.3 \%$ were obtained for the concentration levels of $70 \%, 100 \%$ and $130 \%$, respectively. The quantification and detection limits of the method were evaluated by signal: noise ratio where values found were $0.08 \mu \mathrm{g} / \mathrm{mL}$ and $0.02 \mu \mathrm{g} / \mathrm{mL}$, respectively, thus demonstrating good detectivity.

\section{Apramycin assay by HPLC and turbidimetric methods}

The final stage of this work was the analysis of three batches of apramycin oral soluble powder by the previously validated proposed HPLC method and by the official turbidimetric method, in order to confirm the potency of apramycin. Table I shows all results obtained for both methods, which comply with the limit of $95 \%$ to $105 \%$ established by the BP 2008.

In relation to the turbidimetric method described by the BP 2008, some changes were made concerning the medium and assay design. The British Pharmacopoeia recommends the $\mathrm{H}$ medium, but the $\mathrm{C}$ medium was used, which contains all the constituents (dextrose, tryptone, meat extract) besides buffering agents (dibasic and monobasic potassium phosphate) plus yeast extract, that enriches the medium rendering it more favorable for microbial growth, in turn, contributing to more defined and distinct responses to the different apramycin concentrations. With regard to the design, the British Pharmacopoeia recommends the $3 \mathrm{X} 3$ design, but $5 \mathrm{X} 1$ was employed because more concentration levels are used and this design provides a

TABLE I - Results of apramycin assay obtained for the three batches of oral soluble powder by the HPLC method and by the official turbidimetric assay

\begin{tabular}{|c|c|c|c|c|c|c|}
\hline \multirow{3}{*}{ Sample } & \multicolumn{6}{|c|}{$\%$ Apramycin (under sulfate form) } \\
\hline & \multicolumn{2}{|c|}{ Batch A } & \multicolumn{2}{|c|}{ Batch B } & \multicolumn{2}{|c|}{ Batch C } \\
\hline & HPLC & Turb. Assay & HPLC & Turb. Assay & HPLC & Turb. Assay \\
\hline 1 & 95.33 & 98.53 & 98.73 & 98.76 & 102.59 & 100.38 \\
\hline 2 & 95.64 & 96.03 & 97.95 & 100.43 & 101.72 & 101.23 \\
\hline 3 & 96.10 & 98.76 & 98.45 & 98.36 & 103.72 & 98.64 \\
\hline Average & 95.69 & 97.77 & 98.38 & 98.52 & 102.68 & 100.42 \\
\hline $\mathrm{RSD} *(\%)$ & 0.40 & 1.55 & 0.40 & 0.85 & 0.98 & 0.79 \\
\hline
\end{tabular}

* - Relative Standard Deviation 
TABLE II - Statistical comparison between apramycin assay by HPLC method and by microbiological method for three batches of oral soluble powder

\begin{tabular}{|c|c|c|c|c|c|c|}
\hline & \multicolumn{2}{|r|}{ Batch A } & \multicolumn{2}{|r|}{ Batch B } & \multicolumn{2}{|r|}{ Batch C } \\
\hline & HPLC & Microbiological & HPLC & Microbiological & HPLC & Microbiological \\
\hline Average & 95.69 & 97.77 & 98.71 & 98.52 & 102.68 & 100.42 \\
\hline Variance & 0.15 & 2.29 & 0.56 & 0.71 & 1.01 & 0.63 \\
\hline Observations & 3 & 3 & 3 & 3 & 3 & 3 \\
\hline Hypothesis of average difference & 0 & & 0 & & 0 & \\
\hline Degrees of Freedom & 2 & & 2 & & 2 & \\
\hline Stat $t$ ( $t$ calculated) & -2.420 & & -0.963 & & 2.180 & \\
\hline $\mathrm{P}(\mathrm{T}<=\mathrm{t})$ bi-caudal & 0.137 & & 0.437 & & 0.161 & \\
\hline t critical bi-caudal & 4.303 & & 4.303 & & 4.303 & \\
\hline
\end{tabular}

better estimates of linear equation. Moreover, use of the $5 \mathrm{X} 1$ design allowed apramycin determination of the three batches in a single assay.

Both methods were statistically compared, batch to batch, by the t test to check the correlation between them. As shown in Table II, for each tested batch, $\mathrm{t}_{\text {calculated }}$ was lower than $t_{\text {critical }}$, which allows the assertion that the obtained averages for each method are equivalent to $\alpha=0.05$. Hence, the HPLC and turbidimetric methods can be used interchangeably to assay apramycin in oral soluble powder.

Although the turbidimetric assay described by the British Pharmacopoeia is the official method for determining apramycin potency, it has some drawbacks that can affect the final result. These include the fact that it does not apply to turbid or colored samples; the sample must be in solution; it is highly susceptible to time and incubation temperature variations, rendering method reproducibility hard; while complexity of sample components can cause interference in the transmittance reading.

On the other hand, the use of chemical methods in antibiotics analysis has been increasing, especially by HPLC which, besides providing results faster, also offers other indispensable attributes such as sensitivity, specificity, accuracy and precision, which make its employment advantageous. Considering these findings, the proposed method for determining apramycin in oral soluble powder is a valuable and feasible alternative for apramycin determination that can be applied in quality control analysis of oral soluble powder and in other apramycin dosage formulations in the future.

\section{CONCLUSION}

The LC method proposed for determination of apramycin in oral soluble powder was successfully developed and validated, demonstrating robustness, selectivity, linearity (in 0.02 ton $0.05 \mathrm{mg} / \mathrm{mL}$ range), precision, accuracy and good detectivity, therefore proving suitable for its intended purpose.

Statistical comparison between the proposed LC method and the official microbiological turbidimetric method by the $t$ test detected no significant difference between the two, confirming that the LC method is also reliable and suitable for routine analysis of apramycin assay.

\section{REFERENCES}

ALBRACHT, J.H. Analysis of gentamicin in raw material and pharmaceutical preparations by high performance liquid chromatography. J.Chomatogr., v.389, p.306-311, 1987.

BRITISH pharmacopoeia (Veterinary): 2008. London: Her Majesty's Stationery Office, p.38-40, 122-125, 2008.

BRITISH pharmacopoeia. London: Her Majesty's Stationery Office, v.4, p.A95, A323-A329, 2008.

BRITISH pharmacopoeia. London: Her Majesty's Stationery Office, v.4, p.A279-A285, 2000.

CATURLA, M.C.; CUSIDO, E. High-performance liquid chromatography method for the determination of aminoglycosides based on automed pre-column derivatization with o-phtalaldehyde. J.Chomatogr., v.593, p.69-72, 1992.

CLAES, P.J.; BUSSON, R; VANDERHAEGHE H. Determintation of the component ratio of commercial gentamicins by high performance liquid chromatography using pre-column derivatization. J.Chomatogr., v.298, p. 445-457, 1984. 
DORRESTEIJN, R.C., BERWALD, L.G., ZOMER, G., GOOIJER, C.D., WIETEN, G. Determination of amino acids using o-phthalaldehyde-2-mercaptoethanol derivatization - Effect of reaction conditions. J.Chromatogr. A, v.724, p.159-167, 1996.

EUROPEAN MEDICINES AGENCY. EMA. Committee for Veterinary Medicinal Products. Apramycin. Available at: http://www.ema.europa.eu/docs/en_GB/document library/Maximum_Residue_Limits___Report/2009/11/ WC500010684.pdf Accessed on: 15 out. 2008.

FABRE, H.; SEKKAT M.; BLANCHIN M. D.; MANDROU B. Determination of Aminoglycosides in Pharmaceutical Formulations - II. High Performance Liquid Chromatography. J. Pharm.Biomed. Anal., v.7, n.12, p.1711-1718, 1989.

\section{INTERNATIONAL CONFERENCE ON HARMONIZATION.} ICH. ICH of Technical Requirements for Registration of Pharmaceuticals for Human Use (ICH) Q2 (R1). Geneve, 2006. p.1-13.

ISOHERRANEN N.; SOBACK S. Chromatographic Methods for Analysis of Aminoglycoside Antibiotics. J. AOAC Int., v.82, n.5, p.1017-1045, 1999.

JACOBS, W.A.; LEBURG, W.; MADAJ, E.J. Stability of o-phthalaldehyde-derived isoindoles. Anal. Biochem., v.156, n.2, p.334-340, 1986.

MACNEIL, J.D.; ELLIS, R. Regulatory overview of antibiotic use in food-producing animals in north america and current methods of detection and analysis. In: OKA, H.; NAKAZAWA, H.; HARADA, K.; MACNEIL, J.D. (Eds.). Chemical analysis for antibiotics used in agriculture. Arlington: AOAC International, cap.1, p.2-29, 1995.

MARTINDALE: The complete drug reference. 35.ed. London: Pharmaceutical Press, 2007. p.182.

PERZYNSKI, S.; CANNON, M.; CUNDLIFE, E.; CHAHWALA, S.B.; DAVIES, J. Effects of Apramycin, a novel aminoglycoside antibiotic. Eur. J. Biochem., v.99, p.623, 1979.
STEAD, D.A. Current methodologies for the analysis of aminoglycosides. J. Chromatogr., B: Biomed. Sci. Appl., v.747, n.1/2, p.69-93, 2000.

STOBAUGH, J.F.; REPTA, A.J.; STERNSON, L.A.; GARREN, K.W. Factors affecting the stability of fluorescent isoindoles derived from reaction of $o$-phthalaldehyde and hydroxyalkylthiols with primary amines. Anal. Biochem., v.135, n.2, p.495-504, 1983.

SWEENEY, D.J.; COLEMAN, M.R. Determination of Apramycin in Swine Kidney Tissue by liquid Chromatography with Fluorescence Detection. J. AOAC Int., v.81, n.6, p.1141-1145, 1998.

TATSUTA, K.; AKIMOTO, K.; TAKAHASHI, H.; HAMATSU, T.; ANNAKA, M.; KINOSHITA, M. Total synthesis of aminoglycoside antibiotics, apramycin and saccharocin (KA-5685). Bull. Chem. Soc. Jpn., v.57, p.529-538, 1984.

UNITED States pharmacopoeia. 32.ed. Rockville: United States Pharmacopeial Convention, v.2, p.2489, 2009.

UNITED States pharmacopoeia. 32.ed. Rockville: United States Pharmacopeial Convention, v.1, p.233-237, p.734-736, 2009.

WALTON, J.R. Apramycin, a new aminocyclitol antibiotic. $J$. Antimicrob. Chemother., v.4, p.309-313, 1978.

WEIGAND, R.; COOMBES, R.J. Gentamicin determination by high performance liquid chromatography. J.Chomatogr., v.281, p.381-385, 1983 .

ZHANG, L.; WANG, Z.; CHANG, B.; YANG, W. Determination of Apramycin in Animal Feeds by Solid-Phase Extraction and Liquid Chromatography with Precolumn Derivatization and Fluorescence Detection. J. AOAC Int., v.90, n.4, p.885891, 2007.

Received for publication on $15^{\text {st }}$ January 2010 Accepted for publication on $01^{\text {st }}$ February 2011 